\title{
Characterization of interactions of eggPC lipid structures with different biomolecules
}

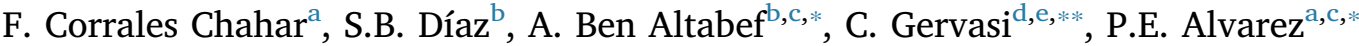 \\ a Instituto de Física, Facultad de Bioquímica, Química y Farmacia, UNT, Ayacucho 471, 4000 Tucumán, Argentina \\ ${ }^{\mathrm{b}}$ Instituto de Química Física, Facultad de Bioquímica, Química y Farmacia, UNT, San Lorenzo 456, T4000CAN S. M. de Tucumán, Argentina \\ ' Instituto de Química del Noroeste Argentino (INQUINOA)-CONICET-Tucumán, Argentina \\ ${ }^{\mathrm{d}}$ INIFTA-CONICET, Facultad de Ciencias Exactas, UNLP, Suc. 4-C.C. 16., 1900 La Plata, Argentina \\ e Facultad de Ingeniería, UNLP, 1 y 47, 1900, La Plata, Argentina
}

\section{A R T I C L E I N F O}

\section{Keywords:}

Annonaceous acetogenins

Ascorbic acid

FTIR

Raman spectroscopy

EIS voltamperometry

\begin{abstract}
A B S T R A C T
In this paper we study the interactions of two biomolecules (ascorbic acid and Annonacin) with a bilayer lipid membrane. Egg yolk phosphatidylcholine (eggPC) liposomes (in crystalline liquid state) were prepared in solutions of ascorbic acid (AA) at different concentration levels. On the other hand, liposomes were doped with Annonacin (Ann), a mono-tetrahydrofuran acetogenin (ACG), which is an effective citotoxic substance. While AA pharmacologic effect and action mechanisms are widely known, those of Ann's are only very recently being studied.

Both Fourier Transformed Infrared (FTIR) and Raman spectroscopic techniques were used to study the participation of the main functional groups of the lipid bilayer involved in the membrane-solution interaction. The obtained spectra were comparatively analyzed, studying the spectral bands corresponding to both the hydrophobic and the hydrophilic regions in the lipid bilayer. Electrochemical experiments namely; impedance spectroscopy (EIS) and cyclic voltamperometry (CV) were used as the main characterization techniques to analyse stability and structural changes of a model system of supported EggPC bilayer in connection with its interactions with AA and Ann.

At high molar ratios of AA, there is dehydration in both populations of the carbonyl group of the polar head of the lipid. On the other hand, Ann promotes the formation of hydrogen bonds with the carbonyl groups.

No interaction between AA and phosphate groups is observed at low and intermediate molar ratios. Ann is expected to be able to induce the dehydration of the phosphate groups without the subsequent formation of $\mathrm{H}$ bonds with them.

According to the electrochemical analysis, the interaction of AA with the supported lipid membrane does not alter its dielectric properties. This fact can be related to the conservation of structured water of the phosphate groups in the polar heads of the lipid. On the other hand, the incorporation of Ann into the lipid membrane generates an increase in the number of defects while changes the dielectric constant. This, in turn, can be associated with the induced dehydration of the phosphate groups.
\end{abstract}

\section{Introduction}

The phospholipids that form cell membranes not only play a structural role in them but they are also involved in cellular regulatory functions such as intracellular second messengers. Evidence suggests that the choline phospholipids can act as second messengers (Fig. 1). Liposomes are a suitable membrane model system to research into the behavior of the cell membranes (Garber et al., 2002).

]The most important effects of Annonaceous acetogenins (ACG) have been described on cancer cell lines, especially those resistant to chemotherapy. Their cytotoxicity is due to the fact that they inhibit ATP synthesis at the mitochondrial complex I. Apparently, inhibition of the respiratory chain would be the most important mechanism through which ACG cause insect larval and pupal mortality. On other hand, Di Toto Blessing et al. (2012) suggested that mitochondrial Complex I inhibition was not the only mode of action of ACG, since insecticidal action would be by the destabilization that occurred in the membrane due to dehydration around the phosphate groups caused by interaction

\footnotetext{
* Corresponding authors at: Instituto de Química del Noroeste Argentino (INQUINOA)-CONICET-Tucumán, Argentina.

** Corresponding author at: INIFTA-CONICET, Facultad de Ciencias Exactas, UNLP, Suc. 4-C.C. 16. 1900, La Plata, Argentina

E-mail addresses: altabef@fbqf.unt.edu.ar (A. Ben Altabef), gervasi@inifta.unlp.edu.ar (C. Gervasi), palvarez@fbqf.unt.edu.ar (P.E. Alvarez).
} 
<smiles>[R]C(=O)OC[C@H](COP(=O)([O-])OCC[N+](C)(C)C)OC([R])=O</smiles>

$R, R^{\prime}=$ fatty acid residues

Fig. 1. The molecular structure of eggPC (L- $\alpha$-Phosphatidylcholine), from egg yolk.

with ACG and their synthetic analogues (Barrachina et al., 2004; Álvarez Colom et al., 2009) (Fig. 2a).

L-Ascorbic acid (also called vitamin $\mathrm{C}$ ), hereafter abbreviated as $\mathrm{L}$ AA; is one of the most essential vitamins for both pharmaceutical and food processing industries. In view of its nutritional significance, varied uses in food and high daily doses necessary for optimum health, L-AA is a very significant vitamin for better public health (Levine, 1986). It has been reported that large doses of vitamin $\mathrm{C}$ increases greatly the rate of production of lymphocytes under antigenic stimulation and it is well established that such a high rate of lymphocyte blastomogenesis is associated with a favorable prognosis of cancer (Lee, 1999; Carr and Frei, 1999; Patterson et al., 1997; Head, 1998; Prasad et al., 1999; Cort, 1982; Barnes and Kodicek, 1972; Hollis et al., 1985). L-AA is known to kill HIV-positive cells and to be useful in HIV-positive patients as a consequence of the potentiating of the immune system (Rivas et al., 1997).

L-AA is a six-carbon keto-lactone (Fig. 2b), a strong reducing agent and serves as an antioxidant. The hydrogen donation from L-AA is considered to be primarily responsible for the antioxidant properties attributed to this molecule. It contains four $\mathrm{OH}$ groups (two enol $\mathrm{OH}$ groups on lactone ring carbons and two $\mathrm{OH}$ groups on the side chain $\mathrm{C}$ atoms). It can be very easily oxidized and changed to dehydroascorbic acid. Its four hydroxyl $(\mathrm{OH})$ groups play important role in its antioxidant property (Singh et al., 2010).

Previous results have indicated that the effects caused by certain compounds on the hydration patterns surrounding phosphate and carbonyl groups of phospholipids can be studied by FTIR and Raman spectroscopy (Díaz et al., 1999, 2003; Hübner and Blume,1998). Our investigations of "membrane-acetogenin" and "membrane-ascorbic acid" interactions were carried out by employing FTIR at different molar ratios of eggPC: biomolecule. In the IR spectra, the frequency shifts of the $\mathrm{PO}_{2}{ }^{-}$and $\mathrm{C}=\mathrm{O}$ stretching-vibration bands were analyzed in comparison with the corresponding bands of eggPC with no addition of the biomolecules.

The knowledge of the specific sites of anchorage of the biomolecules on the lipid membrane together with the structural requirements for the interaction may help us to design synthetic derivatives therapeutically selective.

Supported membranes on top of gold surfaces are interesting models for biomembranes as cell membranes. Supported membranes can be characterized by using electrochemical techniques. In particular, impedance measurements provides monitoring of the dielectric properties of the membranes and their changes related to the interaction with different biomolecules (Steinem et al., 2000; Du et al., 2006; Rameshkumar and Kumaravel, 2017).

Recently, Acetogenins aroused a deep interest in the scientific community, in particular, the effects on human beings of Ann. Since these compounds can be found in different edible fruits and vegetables there is a strong motivation to study the interaction with cell membranes.

Several compounds of acetogenin have been reported to possess anti-proliferative and cytotoxicity properties. Acetogenins, a number of compounds isolated from various parts of Annona muricata, have been shown to exhibit cytotoxicity against various types of cancer cells and to be selectively toxic without harming other healthy cells, in vitro (Rohaizad Md Roduan et al., 2017). The consumption of Annona fruits and herbal teas has been linked to atypical forms of Parkinsonism/dementia in the French West Indies, as well as in other tropical areas. Since evidence of possible neurotoxic long-term effects in humans was brought to light, estimation of exposure to acetogenins raised the attention of several research groups (Bonneau et al., 2017) Custard apple (Annona squamosa L.) is an edible tropical fruit, and is also called sugar apple or sweet sop. As a famous tropical fruit, it is consumed in lots of countries. Botanical extracts have been used as a source of medicinal agents for thousands of years (Chen et al., 2016). The abnormal accumulation of the axonal microtubule-associated protein tau in the somatodendritic compartment of neurons is the defining hallmark of a group of neurodegenerative disorders termed tauopathies (Goedert et al., 2000; Trojanowski and Lee, 2005). Rare mutations in the tau gene (MAPT, MIM\# 157140), located on chromosome 17q21, cause autosomal dominant tauopathies called frontotemporal dementia with Parkinsonism linked to chromosome-17 (FTDP-17). Other forms of frontotemporal dementias, argyrophilic grain disease, corticobasal degeneration, Pick's disease and progressive supranuclear palsy (PSP) are examples of the more frequent sporadic tauopathies. The etiology of the sporadic tauopathies is, at present, largely unknown and requires further scientific attention.

A particular variant of a sporadic tauopathy, endemic to the island of Guadeloupe, has been linked in clinical case-control studies to the consumption of fruit and infusions of the leaves of Annona muricata (Caparros-Lefebvre et al., 2002; Lannuzel et al., 2007), which contain annonaceous acetogenins, a large and unique family of potent lipophilic inhibitors of mitochondrial complex I (Bermejo et al., 2005). Annonacin, the major acetogenin in Annona muricata, readily crosses biological membranes, such as the blood-brain barrier (Champy et al., 2004) and the neuronal cell membrane (Lannuzel et al., 2003) due to its high lipophilicity, and therefore has easy access to cerebral mitochondria upon systemic exposure. Low nanomolar concentrations of annonacin reduce adenosine-triphosphate (ATP) levels and induce a redistribution of tau protein from the axon to the somatodendritic compartment of striatal neurons in vitro (Escobar-Khondiker et al.,

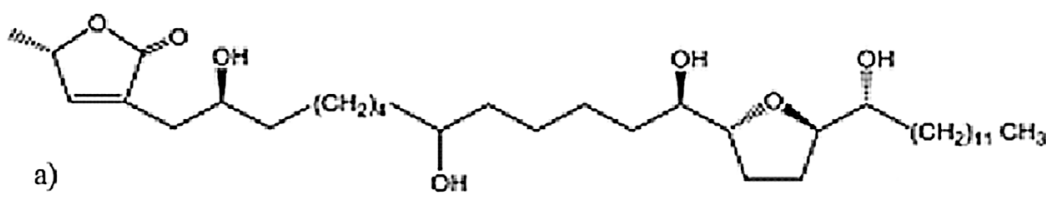

Fig. 2. The molecular structures of biomolecules a) annonacin and b) ascorbic acid.<smiles>O=C1O[C@H]([C@@H](O)CO)C(O)=C1O</smiles> 
2007). After chronic systemic infusion in rats, annonacin reduces cerebral ATP levels and causes neuronal cell loss and gliosis in the brain stem and basal ganglia (Champy et al., 2004).

The quantities of annonacin in the fruit and traditionally prepared infusions of leaves of Annona muricata are such that a cumulative dose sufficient to cause neurodegeneration in rats can be attained in humans by regular consumption within a year (Champy et al., 2005). Therefore, it appears plausible that annonacin or other annonaceous acetogenins might be implicated in the etiology of the tauopathy of Guadeloupe.

Since acetogenins are produced exclusively by annonaceous plants, which do not have a global distribution, but are grown and consumed mainly in tropical and subtropical zones, it has been hypothesized that other compounds with similar biochemical properties might be implicated in the etiology of sporadic neurodegenerative tauopathies with a more global prevalence (Höllerhage et al., 2009).

Likewise, regarding ascorbic acid (AA) and its action on human health many aspects remain still unclarified particularly those related to the interaction with cell tissues. Consequently, there is a great interest in this issue and in the development of biosensors to sense its concentration in different media.

Humans need to obtain vitamin $\mathrm{C}$ from their diet due to the lack of $\mathrm{L}^{-}$ gulono- $\gamma$-lactone oxidase involved in AA (vitamin C) synthesis (Lachapelle and Drouin, 2011; Gutiérrez-Quequezana et al., 2018). Owing to its importance in water-soluble vitamins, AA has been widely investigated as a target analyte for the prevention and treatment of diseases, such as scurvy, common cold, mental illness, and cancer, related to its antioxidant properties (Zhang et al., 2018).

Additionally, due to the fact that the concentration of AA is on a milli molar level in the central nervous system and much less in other humoral fluids, the development of a simple and rapid method for the determination of AA with high sensitivity is desirable in a vast range of areas such as foods, drugs, and cosmetic applications (Fana et al., 2017).

This work aims at gaining insight into the characteristics of the membrane-biomolecule interaction in order to understand the action mechanisms of the biomolecules, their effectivity and physicochemical properties. Motivation to select these two biomolecules was provided by their different chemical characteristics (AA is hydro soluble while Ann is liposoluble) what is expected to exhibit different ways of interacting with the lipid membrane. Moreover, while AA pharmacologic effect and action mechanisms are widely known, those of Ann's are only very recently being studied (Salama and Arias-Carrión, 2011; Vieira Machado de Moraes et al., 2016). Over-consumption of Graviola fruits containing Ann has caused an atypical form of Parkinson's disease.

\section{Experimental}

\subsection{Lipids and chemicals}

Synthetic L- $\alpha$-Phosphatidylcholine (eggPC) with a purity approx. $99 \%$, positively charged dimethyldioctadecyl-ammoniumchloride (DODAC) and Tris (tris-hydroxymethyl aminomethane) with a purity $\geq 99.8 \%$ were purchased from Sigma-Aldrich Inc. (St. Louis, MO, USA); 3-Mercaptopropionic acid (Ac MP) from Merck (Germany), $(\mathrm{L}+)$ Ascorbic acid Pro-analysis (USP). Purity was checked by thinlayer chromatography, and lipids were used without further purification. $(\mathrm{L}+)$ Ascorbic acid purity was checked by FTIR spectra. All other chemicals were of analytical grade, and tridistilled water was employed in all the experiments.

The annonaceous acetogenin Annonacin (Ann, Fig. 2a) was isolated and purified from the seeds of Annona cherimolia at the Institute of Organic Chemistry of the Faculty of Biochemistry, Chemistry and Pharmacy of the National University of Tucumán, R. Argentina. It was identified by its spectroscopic characteristics compared to the previously reported literature data.

\subsection{Lipid sample preparation}

Multilamellar vesicles (MLVs) were prepared following Bangham's method (Bangham et al., 1974) to study biomolecules (Ann and AA) and eggPC interaction. The lipid pure and samples at different molar ratios (0.38:1 and 0.77:1) of Ann:eggPC in chloroform solution were dried to form a film under a nitrogen stream that was left for $24 \mathrm{~h}$ under vacuum to ensure proper solvent removal. The samples were rehydrated and suspended in deuterated water. The pure Ann compound was obtained in a small amount $(\mu \mathrm{g})$ from a plant extract, so the available concentrations were used.

On the other hand, the lipid was rehydrated in $\mathrm{D}_{2} \mathrm{O}$ solutions of different concentrations of AA (25, 50, 100 and $200 \mathrm{mM})$. Or equivalently in terms of molar fractions of AA:eggPC: 0.34:1, 0.77:1, 1.50:1 and 3.10:1, respectively. In the case, values of adequate concentrations were used for the change in the signals using the Raman and FTIR spectroscopic techniques.

The mechanical dispersion of the hydrated lipid film was made under vigorous by shaking for $15 \mathrm{~min}$, resulting in an opalescent suspension of MLVs, at room temperature. The final lipid concentration was $50 \mathrm{mg} / \mathrm{mL}$.

\subsection{Preparation of supported lipid bilayers (SLBS) on $A u$}

Unlike a vesicle or a cell membrane in which the lipid bilayer is rolled into an enclosed shell, a supported bilayer is a planar structure sitting on a solid support. Because of this, only the upper face of the bilayer is exposed to the free solution. One of the greatest advantages of the supported bilayer is its stability. SLBs will remain largely intact even when subject to high flow rates or vibration and the presence of holes will not destroy the entire bilayer (Purrucker et al., 2001). SLBs were obtained by attaching the lipid bilayer to the surface of the gold electrode through a negatively charged self-assembled monolayer of Ac MP. For this purpose the electrode was incubated for at least $1 \mathrm{~h}$ in an ethanolic solution of $0.1 \mathrm{M}$ Ac MP. The lipidic film (Bangham et al., 1974) was prepared as indicated in Section 2.2, from mixtures of: $80 \%$ eggPC and $20 \%$ dimethyl dioctadecyl ammonium chloride (DODAC) and another $76.4 \%$ eggPC, $19.1 \%$ DODAC and $4.5 \%$ Ann. DODAC, a positively charged molecule, acts by electrostatically binding the lipid bilayer to the self-assembled monolayer. MLV́s were formed by vigorous shaking and rehydration of the film in the presence of $10 \mathrm{mM}$ Tris buffer solution with $0.1 \mathrm{M}$ potassium chloride $(\mathrm{KCl}), \mathrm{pH}$ 7.4. A suspension of multilamellar vesicles of final concentration of $3 \% \mathrm{w} / \mathrm{v}$ was obtained. To ensure that only one lipid bilayer was attached to the gold surface, the MLV's suspension was extruded with LIPEX ${ }^{\mathrm{TM}}$ Extruder (Bergera et al., 2001; Olson et al., 1979), obtaining unilamellar vesicles (LUV's), with which the electrode, containing the Ac MP's self-assembled monolayer, was incubated for at least $15 \mathrm{~h}$ (Fig. 3).

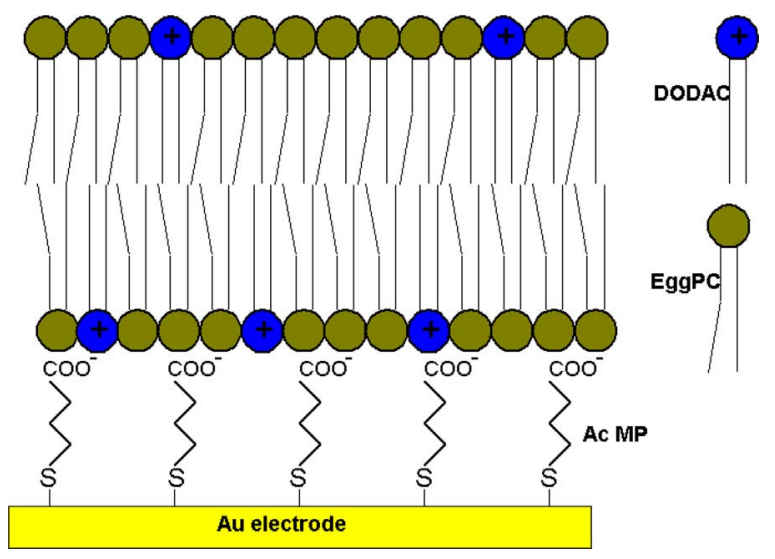

Fig. 3. Diagram of a supported bilayer (Alvarez et al., 2007). 


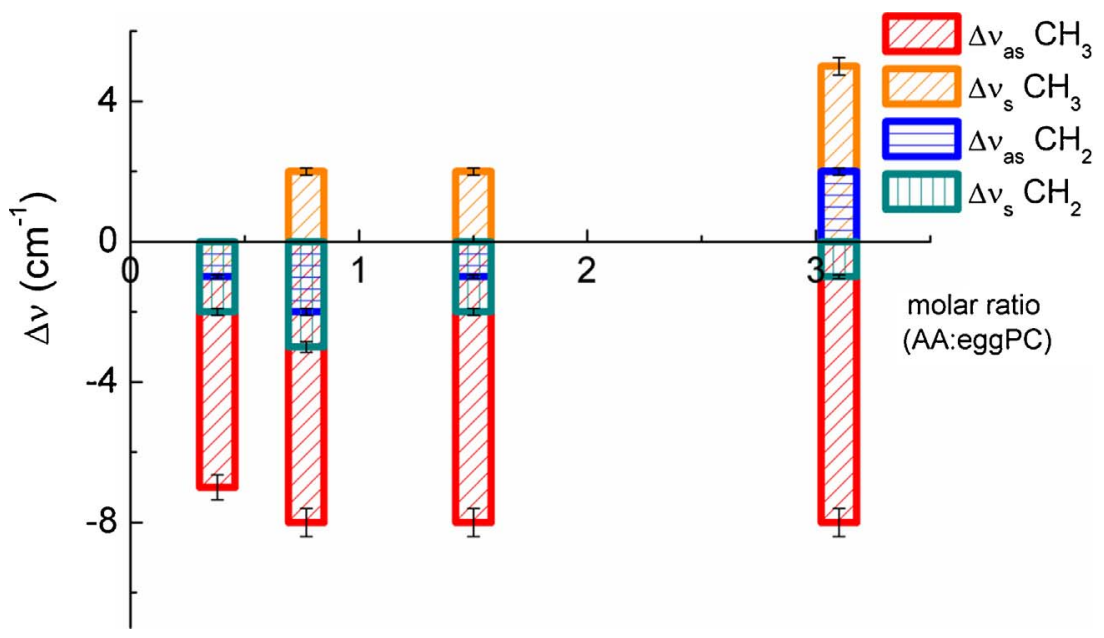

Fig. 4. Effect of AA on the position of the vibrational bands of Raman spectra for the $\mathrm{CH}_{2}$ and $\mathrm{CH}_{3}$ groups in eggPC at liquid crystalline state.

\subsection{FTIR and Raman spectroscopic measurements}

\subsubsection{FTIR measurements}

FTIR measurements were carried out in a Perkin Elmer GX spectrophotometer, provided with a DTGS detector. The spectra of biomolecules with the phospholipid were acquired in a demountable cell for liquid samples with $\mathrm{ZnSe}$ windows. The working temperature cell was $25{ }^{\circ} \mathrm{C}$, controlled using a Peltier-type system with accuracy of $\pm 0.1^{\circ} \mathrm{C}$. The resolution of the equipment employed was $1 \mathrm{~cm}^{-1}$. A total of 64 scans were done in each condition and the spectra were analyzed using the OMNIC v.7.2 mathematical software provided by the manufacturer.

The bands in the mixtures were assigned to the carbonyl and phosphate groups by comparison with pure lipids. The $\mathrm{C}=\mathrm{O}$ bands, are broad and overlapping. The Fourier deconvolution was used to estimate the frequencies of the component bands, followed by curve-fitting to obtain the bandwidth and the intensity (band narrowing factors: 1.6-2.2). Spectra of pure $\mathrm{D}_{2} \mathrm{O}$ were subtracted in all analyzed samples to avoid solvent interference with the phosphate group.

Deconvolution was used to obtain the peak frequencies of the component bands reported for the two populations of carbonyls: the non-hydrated $\left(1737 \mathrm{~cm}^{-1}\right)$ and the hydrated $\left(1722 \mathrm{~cm}^{-1}\right)$ populations in the fluid state (Díaz et al., 1999; Hübner and Blume, 1998; Disalvo et al., 2002; Pohle et al., 1998). The shifts of these two populations were studied as a function of the biomolecules/lipid ratio of eggPC in liquid crystalline state.

\subsubsection{RAMAN measurements}

The vibrational Raman spectra of samples were recorded by using a confocal Thermo Scientific-DXR Raman Microscope. The microscope is equipped with a high resolution motorized platen, a set of Olympus optical objectives, lighting module bright field/dark field trinocular viewer, Olympus camera of 2048 pixels with CCD detector. The confocal system is real, with opening/hole matched with the point of symmetry of the excitation laser. The resolution is $2 \mu \mathrm{m}$ in depth profiles. The standard spatial resolution was better than $1 \mu \mathrm{m}$.

The spectra were obtained at room temperature, by using a laser diode-pumped solid state (DPSS) of $532 \mathrm{~nm}$ with a power of $10 \mathrm{~mW}$; the optical objective used was a 10X with an optical opening of $25 \mu \mathrm{m}$. The spectra were analyzed using the $\mathrm{OMNIC}^{\mathrm{TM}}$ program for Dispersive Raman.

\subsection{Electrochemical measurements}

Electrochemical experiments were obtained by using a three-electrode cell and a Zahner IM6 electrochemical workstation. The working $\mathrm{Au}$ electrode had an area of $1 \mathrm{~cm}^{2}$. The counter electrode was a platinum sheet, and a saturated calomel electrode (SCE) was used as the reference electrode. All potentials in this work are referred to the SCE $(0.2412 \mathrm{~V}$ with respect to the normal hydrogen electrode). Voltammetric experiments were run at a sweep rate of $50 \mathrm{mV} \mathrm{s}^{-1}$. Impedance data were recorded in the $30 \mathrm{kHz}-0.01 \mathrm{~Hz}$ frequency range with perturbation signal amplitude of $10 \mathrm{mV}$.

\section{Results/discussion}

\subsection{Vibrational spectroscopy measurements}

Biomolecules (AA and Ann) interactions with a lipid membrane of eggPC were studied by Fourier Transformed Infrared (FTIR) and Raman spectroscopic techniques. The obtained spectra were comparatively analyzed by a study of the spectral bands corresponding to the inner and interphase regions of the lipid bilayer.

\subsubsection{Hydrophobic region}

3.1.1.1. FTIR measurements. Moderate wavenumber ranges in the FTIR spectrum may be assigned to different parts of the lipid molecule. Detailed information about the molecular interactions can be obtained for hydrated liposomes.

Changes in the wavenumbers of symmetric and antisymmetric stretching vibrations of the methyl and methylene groups inside the lipid bilayer were not significant within the experimental error for both biomolecules, in the liquid crystalline phases (Tables S1 and S2).

3.1.1.2. Raman measurements. Raman measurements show significant displacements in the $\mathrm{CH}_{3}$ symmetric and antisymmetric stretchings to lower frequencies for the Ann: eggPC complex but only in the $\mathrm{CH}_{3}$ antisymmetric stretching for the AA: eggPC complex, which could indicate an increase in disorder in the liquid crystalline state induced by biomolecules Annonacin and L-ascorbic acid respectively (Tables S3 and S4 and Figs. 4 and 5).

The region between 1000 and $1200 \mathrm{~cm}^{-1}$ corresponds to the stretching vibrations of the $\mathrm{C}-\mathrm{C}$ bonds of the acyl chains of the phospholipids. The peaks of $1126 \mathrm{~cm}^{-1}$ and $1067 \mathrm{~cm}^{-1}$ are assigned to such stretches of the trans conformations, while the peak of $1089 \mathrm{~cm}^{-1}$ corresponds to the gauche conformations. The peak intensity ratio $\mathrm{I}_{1089}$

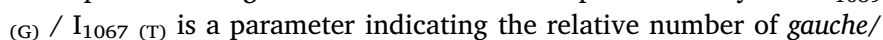
trans rotamers in the acyl chains of the phospholipids. Other bands of interest whose intensity ratios are useful are as follows: $\mathrm{I}_{2935} / \mathrm{I}_{2851}$ (I $\left.\nu_{\mathrm{s}} \mathrm{CH}_{3} / \mathrm{I} \nu \nu_{\mathrm{s}} \mathrm{CH}_{2}\right)$ and $\mathrm{I}_{2885} / \mathrm{I}_{2851}\left(\mathrm{I} \nu_{\mathrm{as}} \mathrm{CH}_{2} / \mathrm{I} \nu_{\mathrm{s}} \mathrm{CH}_{2}\right)$ which are indicative of the interaction between the hydrocarbon and the conformation. More specifically, these intensity ratios are used to indicate changes in the order / disorder ratio of the hydrocarbon chains (Snyder, R. G. y col. 1982) (Snyder et al., 1982; Fox and Harris, 2010; Fox, 2007). 


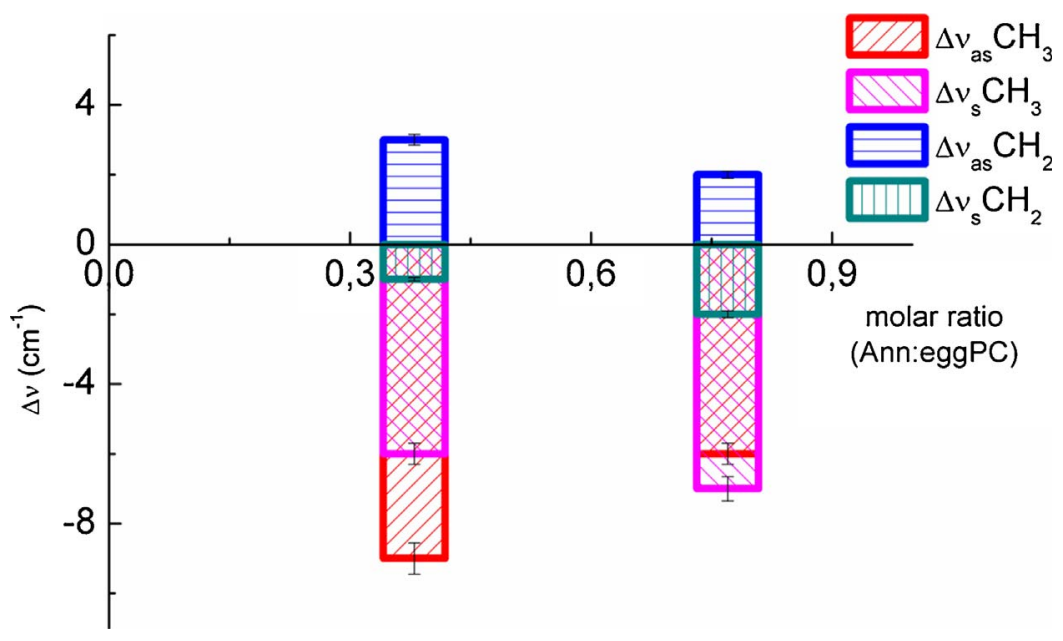

Fig. 5. Effect of Ann on the position of the vibrational bands of Raman spectra for the $\mathrm{CH}_{2}$ and $\mathrm{CH}_{3}$ groups in eggPC at liquid crystalline state.
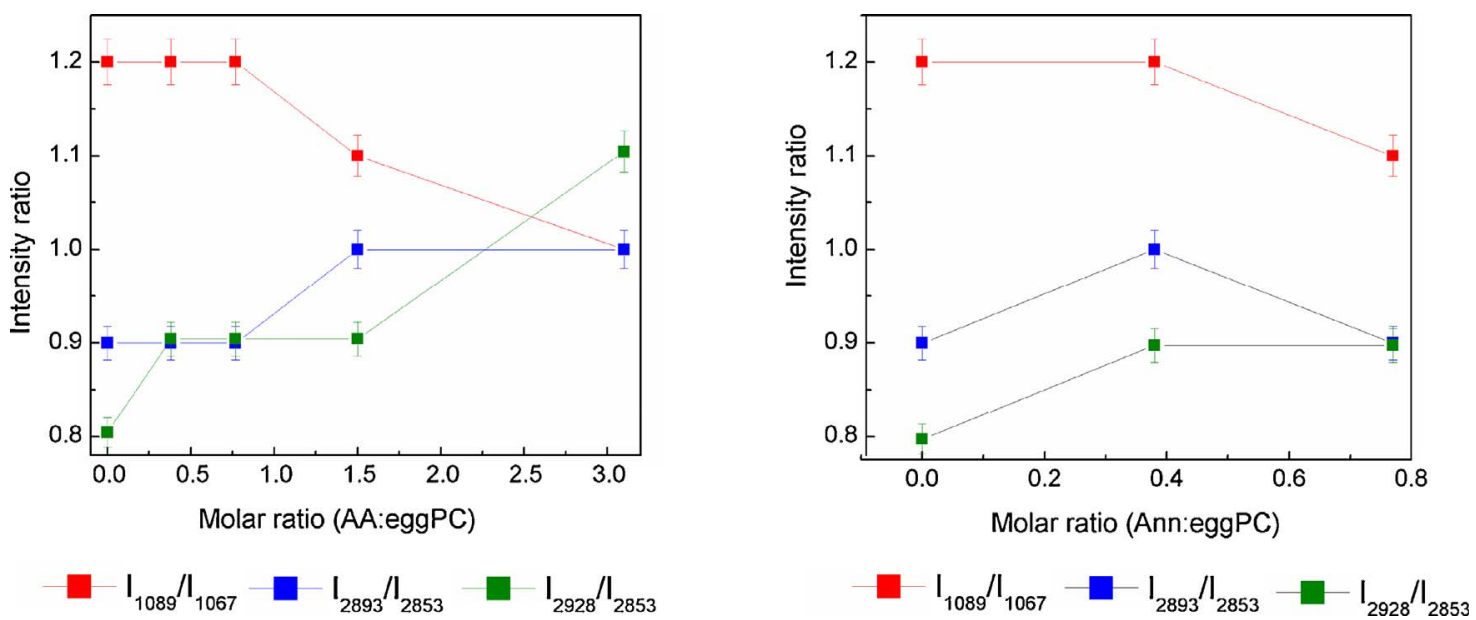

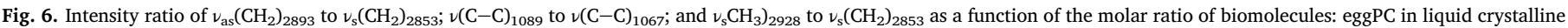
state.

At higher concentrations of AA slightly decreases the ratio of intensities $\mathrm{I}_{1089(\mathrm{G})} / \mathrm{I}_{1067}$ (T) in 0.2, as well as for the greater Ann:eggPC molar ratio in 0.1. It was observed that in the presence of both biomolecules, the gauche rotamers decrease slightly compared with trans, in liquid crystalline state. The intensity ratio of the peaks of $\mathrm{I} \mathrm{v}_{\mathrm{as}}\left(\mathrm{CH}_{2}\right)$ / $\mathrm{I} \nu_{\mathrm{s}}\left(\mathrm{CH}_{2}\right)$ is specifically indicative of the rotational disorder and the intermolecular coupling of the chains. At higher concentrations of AA there is a slight increase (0.1) in the ratio of intensities. For Ann:eggPC it could be said that there is practically no modification. The Intensity ratio of the peaks $\mathrm{I}_{\mathrm{s}}\left(\mathrm{CH}_{3}\right) / \mathrm{Iv}_{\mathrm{s}}\left(\mathrm{CH}_{2}\right)$ is related to the degree of rotational and vibrational freedom of the terminal methyl groups. As the concentration of AA increases, there is an increase in the ratio of intensities (0.3), which would indicate an increase in the rotational and vibrational freedom of the terminal methyl groups. In the case of Ann: EggPC there is an increase of 0.1 for both molar ratios, in liquid crystalline state. (Tables S5 and S6 and Fig. 6).

\subsubsection{Hydrophilic region}

3.1.2.1. FTIR measurements. The interphase region (Disalvo and de Gier, 1983) may be characterized by FTIR spectra of the biomolecules: eggPC systems, which are strongly dependent on the state of hydration and are susceptible to hydrogen bonding. In the IR spectra, the wavenumber shifts of the $\mathrm{PO}_{2}{ }^{-}$and $\mathrm{C}=\mathrm{O}$ stretchingvibration bands were analyzed in comparison with the corresponding bands of eggPC without addition of the biomolecules.

3.1.2.2. $C=O$ group. It has been reported that the main $\nu \mathrm{C}=\mathrm{O}$ peak in diacyl lipids can be unfolded into at least two components that correspond to the $v \mathrm{C}=\mathrm{O}$ vibrational modes of non-bonded (free) and H-bonded (bond) conformers of the $\mathrm{C}=\mathrm{O}$ group (Díaz et al., 1999; Hübner and Blume, 1998; Disalvo and de Gier, 1983). To investigate Hbonding interactions between the biomolecules and the $\mathrm{C}=\mathrm{O}$ lipid groups, deconvolution of the main band of $\nu \mathrm{C}=\mathrm{O}$ (located at $\sim 1734 \mathrm{~cm}^{-1}$ for pure lipid) into three components $\left(\nu \mathrm{C}=\mathrm{O}_{\text {bond }}, \nu\right.$ $\mathrm{C}=\mathrm{O}_{\text {free }}$ and $\vee \mathrm{C}=\mathrm{O}_{\text {biomolecules }}$ ) were performed. The higher wavenumber band component $\left(1740 \mathrm{~cm}^{-1}\right)$ was assigned to the free $\nu$ $\mathrm{C}=\mathrm{O}$ groups $\left(\nu \mathrm{C}=\mathrm{O}_{\text {free }}\right.$ ), whereas the lower wavenumber component $\left(1731 \mathrm{~cm}^{-1}\right)$ was attributed to the $\nu \mathrm{C}=\mathrm{O}$ vibration of $\mathrm{H}$-bonded conformers $(\nu \mathrm{C}=\mathrm{O}$ bond $)$ in eggPC liposomes. Tables S7 and S8 and Fig. 7 display the position of the carbonyl stretching bands in MLV's as measured by FTIR.

It was observed that at the molar ratio $0.38: 1$ for AA: eggPC there is a slight interaction with formation of hydrogen bonds between the AA and the $\mathrm{C}=\mathrm{O}$ group, in both populations of the eggPC carbonyl groups. At higher molar ratios there is a different qualitative behavior which would be attributed to the loss of structured water molecules in both populations of the carbonyl group in the region of the polar head of the lipid (Fig. 7).

It can be seen that at $25^{\circ} \mathrm{C}$ (liquid crystalline phase) Ann displaces the band assigned to both carbonyl populations to lower frequencies, suggesting the formation of hydrogen bonds between Ann and the carbonyl groups (Fig. 7).

3.1.2.3. $\mathrm{PO}_{2}{ }^{-}$group. In fully hydrated phosphatidylcholine in the 


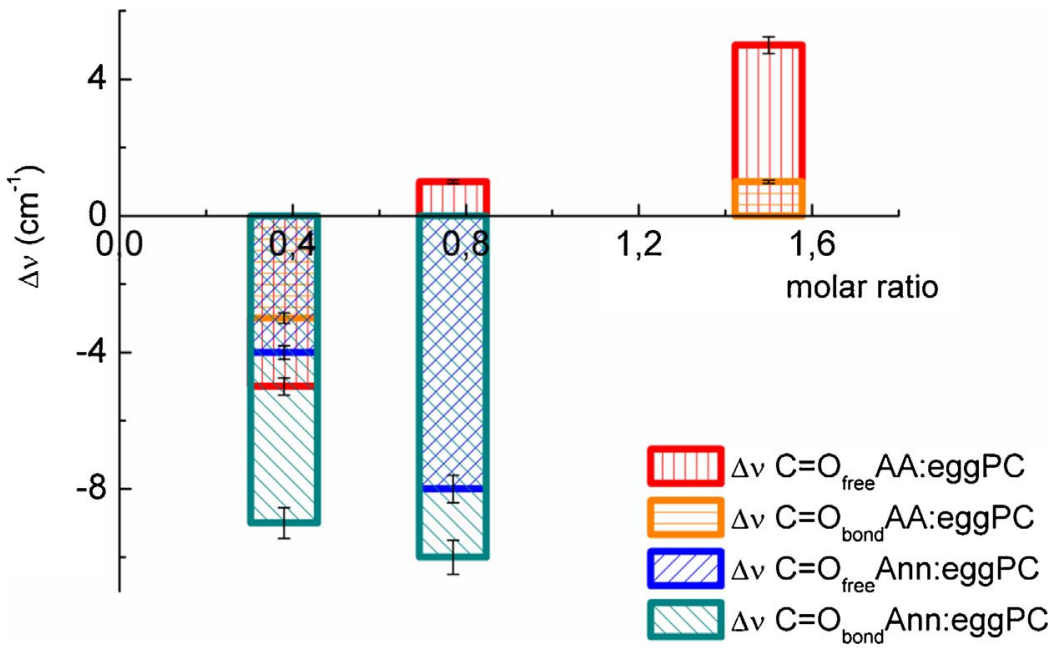

Fig. 7. Wavenumber variation of the $\mathrm{CO}$ stretching in connection with the increasing biomolecule: DPPC molar ratio, at $25^{\circ} \mathrm{C}$.

liquid crystalline state, the characteristic phosphate group vibrational bands assigned to the $\mathrm{PO}_{2}{ }^{-}$antisymmetric stretching mode $\left(\nu_{\text {as }} \mathrm{PO}_{2}{ }^{-}\right)$ is centered at $1229.5 \mathrm{~cm}^{-1}$ and the $\mathrm{PO}_{2}{ }^{-}$symmetric stretching mode $\left(\nu_{\mathrm{s}} \mathrm{PO}_{2}^{-}\right)$at $1085.0 \mathrm{~cm}^{-1}$. It is widely accepted that the frequency of the vibration $\left(\mathrm{V}_{\mathrm{as}} \mathrm{PO}_{2}{ }^{-}\right)$is very sensitive to lipid hydration mainly because of direct $\mathrm{H}$ binding to the charged phosphate oxygens (Mantsch and McElhaney, 1991).

For the $\mathrm{PO}_{2}{ }^{-}$antisymmetric vibration band $\left(1213 \mathrm{~cm}^{-1}\right.$ for pure eggPC), at different molar ratios of the AA:eggPC complex, no significant interaction is observed within the experimental error. However, the $\mathrm{PO}_{2}{ }^{-}$antisymmetric stretching for the Ann:eggPC complex, is slightly affected towards higher frequencies with respect to the pure lipid (Tables S9 and S10 and Figs. 8-10).These results suggest that Ann would be able to induce the dehydration of the phosphate groups without the subsequent formation of $\mathrm{H}$ bonds with them.

No significant changes are observed in the band frequencies of $\mathrm{PO}_{2}{ }^{-}$symmetric stretching $\left(1088 \mathrm{~cm}^{-1}\right)$, in both cases (AA:eggPC and Ann:eggPC complexes). This may be due to the fact that in the fluid state the polar groups are more hydrated, which makes the water displacement for biomolecules insertion more difficult.

\subsection{Electrochemical characterization of SLB on Au.Electrochemical characterization of SLB on $A u$}

Voltammetric response (a) in Fig. 11 corresponds to an Au electrode covered by the SLB in solution of buffer Tris $10 \mathrm{mM}, \mathrm{pH}=7.4$. Voltammogram (b) shows the same modified electrode but in the presence of ascorbic acid (AA) in the electrolyte. This response shows the oxidation of AA with a single peak shifted towards anodic potentials. Finally, voltammetric curve (c) results for the redox behavior of AA on a Au electrode in the absence of the SLB. Two anodic peaks can be clearly observed without the inhibition brought about by the lipid membrane. Thus, in spite of a marked barrier effect by the SLB, AA still exhibits a small degree of anodic oxidation, although in a much more irreversible fashion.

Fig. 12 contains the voltammetric response for a $\mathrm{Au}$ electrode modified by the SLB in solution $1 \mathrm{mM} \mathrm{Fe}(\mathrm{CN})_{6}{ }^{4-/ 3-}$ and $0.15 \mathrm{M} \mathrm{KCl}$ as supporting electrolyte. Additionally, the voltammetric response for an Au electrode modified by the SLB doped with Annonacin (Ann) in the same solution is also shown. In these experiments $\mathrm{Fe}(\mathrm{CN})_{6}{ }^{4-/ 3-}$ is used as a redox couple marker since Ann has no electrochemical transformation, at least in the studied potential window. Moreover, since Ann is not water soluble, it was incorporated into the lipid membrane. Only a slight increase in the anodic current can be observed in the presence of Ann that could, in principle, indicate an increase in the number of defects in the lipid membrane.

Fig. 13 shows impedance data for a Au electrode covered by the SLB in solution of buffer Tris. Impedance data analysis was performed according parameters identification procedures by using complex nonlinear least squares (CNLS) fitting based on the Marquardt-Levenberg

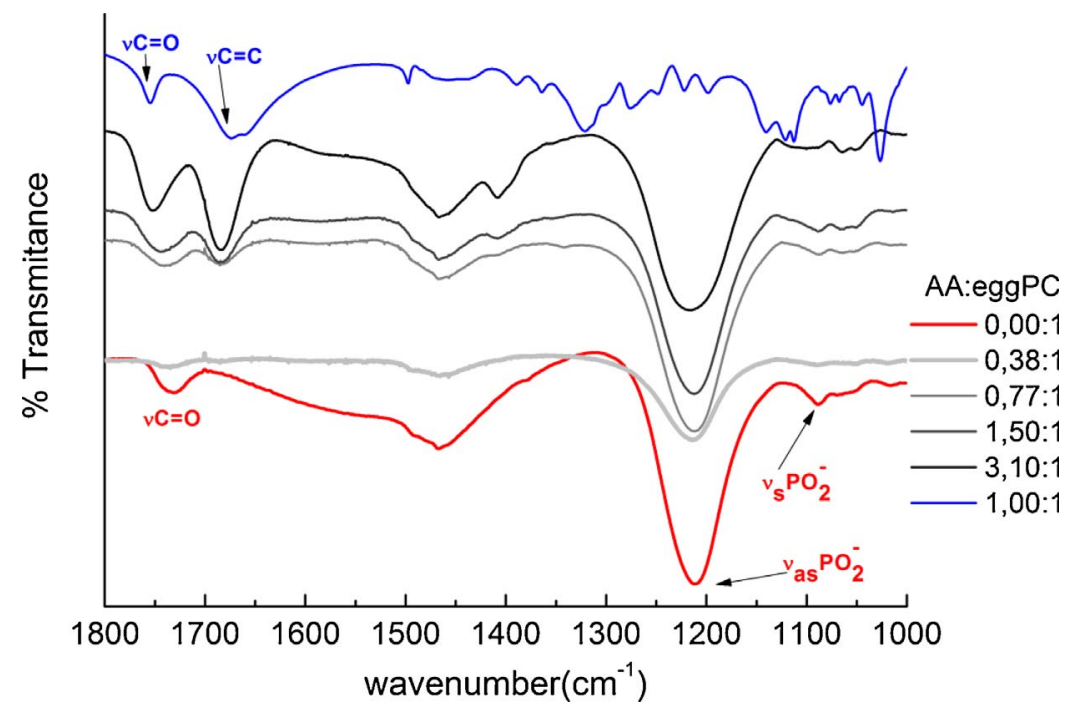

Fig. 8. FTIR spectra of the pure eggPC multilamellar vesicles and the AA:eggPC complexes, at different ratio molar, in the region corresponding. $\mathrm{C}=\mathrm{O}$ and $\mathrm{PO}_{2}{ }^{-}$. 


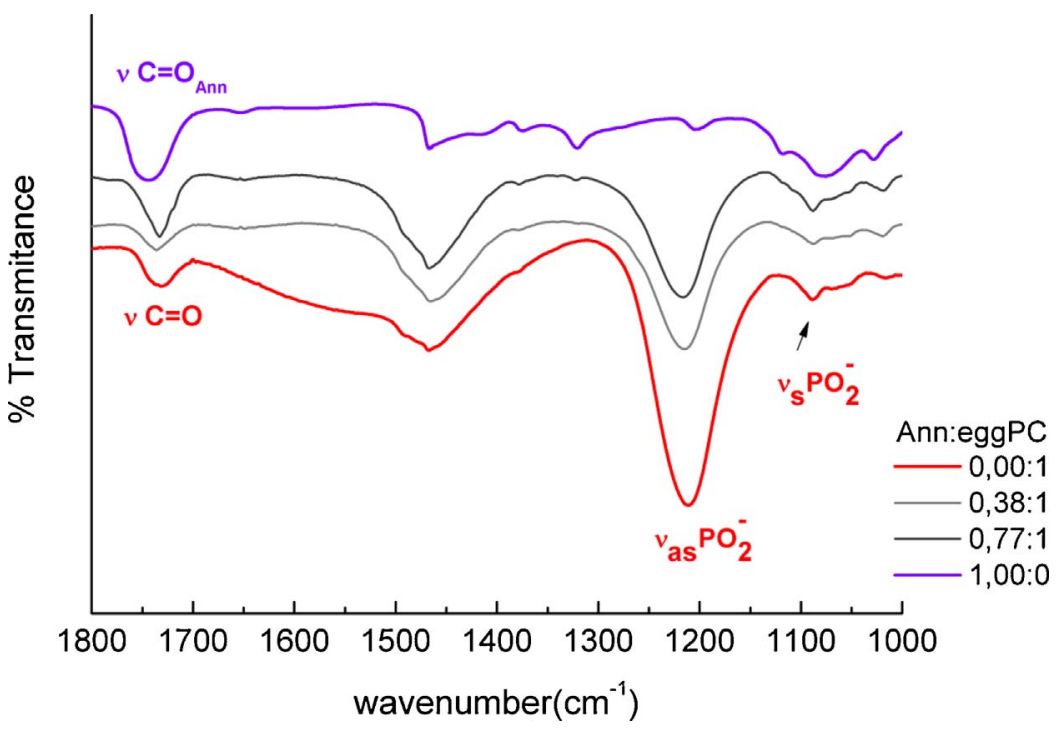

Fig. 9. FTIR spectra of the pure eggPC multilamellar vesicles and the Ann:eggPC complexes, at different ratio molar, in the region corresponding. $\mathrm{C}=\mathrm{O}$ and $\mathrm{PO}_{2}{ }^{-}$.

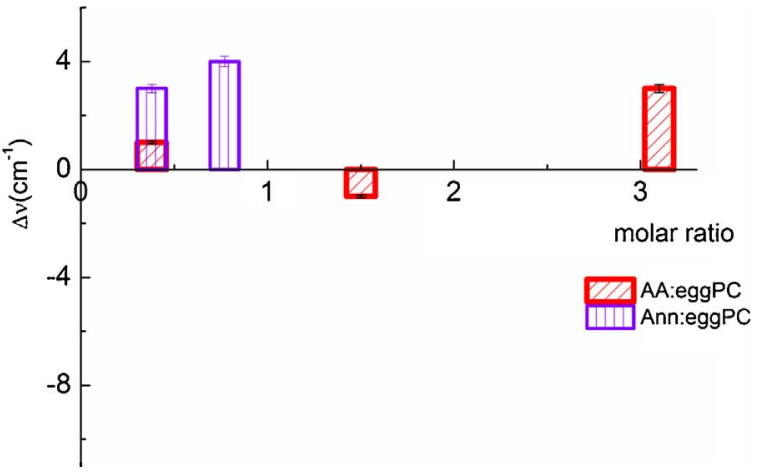

Fig. 10. Effect of AA and Ann on the position of the vibrational bands of FTIR for the $\mathrm{PO}_{2}{ }^{-}$groups in eggPC, at $25^{\circ} \mathrm{C}$.

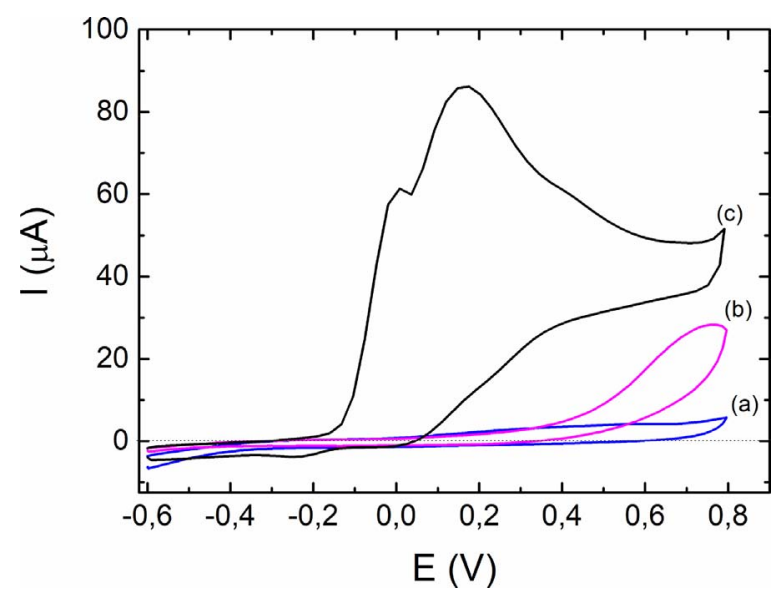

Fig. 11. Voltammograms for Au electrodes modified by the SLB in solution of buffer Tris (a) and in solution containing $7 \mathrm{mM}$ ascorbic acid (AA) (b) and for an unmodified $\mathrm{Au}$ electrode in solution containing $7 \mathrm{mM}$ AA (c).

algorithm. Non-linear optimizations based on the Marquardt-Levenberg algorithm contained a weighting function that ensured a more uniform relative distribution of the differences over all frequencies.

A single capacitive relaxation characterizes the measured impedance behaviors which were fitted to the impedance of an equivalent circuit resulting from a series connection of the electrolyte resistance $R_{e}$ and an impedance element containing the parallel connection of a capacitor and a large resistance as shown in Fig. 14. The membrane

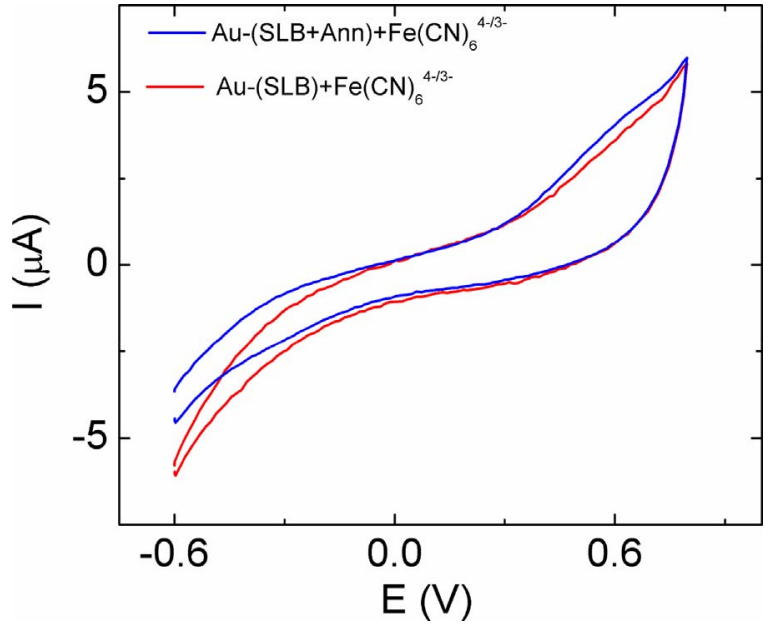

Fig. 12. Voltammograms for a Au electrode modified with the SLB in solution containing $1 \mathrm{mM} \mathrm{Fe}(\mathrm{CN})_{6}{ }^{4-/ 3-}$ (red trace) and with the SLB doped with Annonacin (Ann) in the same solution as before (blue trace). (For interpretation of the references to colour in this figure legend, the reader is referred to the web version of this article.)

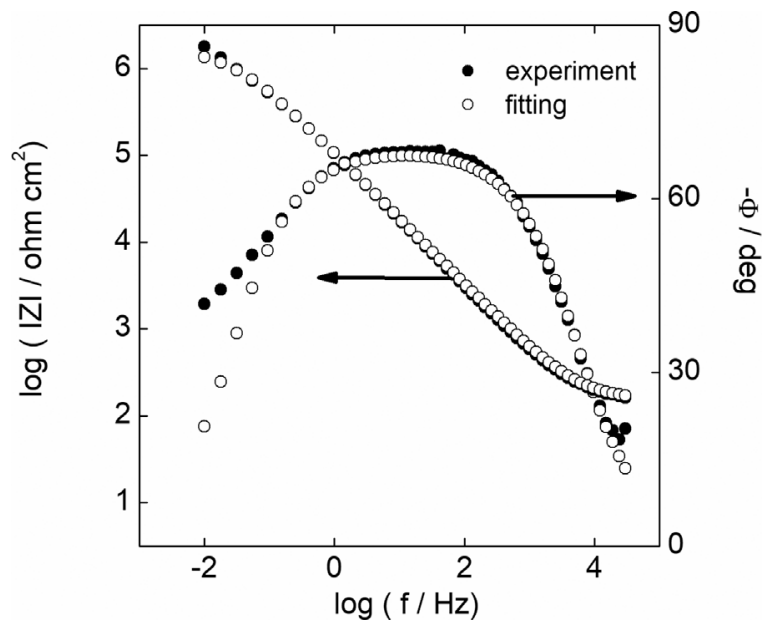

Fig. 13. Bode plots for experimental and fit impedance spectra measured with a $\mathrm{Au}$ electrode modified with the SLB in solution of the buffer tris. 


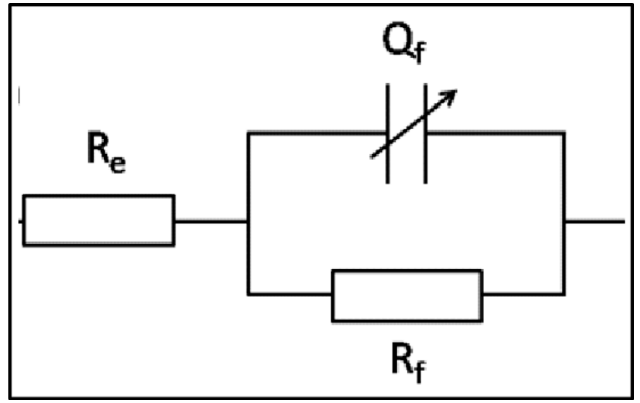

Fig. 14. Equivalent circuit used to fit impedance spectra.

capacitance is represented here by a constant phase element (CPE) Q in parallel connection with the membrane resistance $R_{f}$.

Fig. S1 shows impedance data for a Au electrode covered by the SLB in solution of buffer Tris and $7 \mathrm{mM}$ AA. The same dynamic behavior as in Fig. 14 can be observed.

The impedance of a CPE is given by:

$Z_{C P E}=\frac{1}{(j w)^{n} Q}$

Accordingly, the membrane capacitance $\mathrm{C}_{\mathrm{m}}$ can be calculated (Brug et al., 1984) as

$C_{m}=\frac{Q}{\left(R_{e}^{-1}+R_{f}^{-1}\right)^{1-n}}$

Best-fit parameters of impedance data in Figs. 13 and S1 are given in Table 1 . Values for the exponent $\mathrm{n}$ are close to 1 , indicating a capacitance behavior.

Then, for the SLB covered electrode $\mathrm{C}_{\mathrm{m}} \approx 2.410^{-5} \mathrm{~F} \mathrm{~cm}^{-2}$ while in the presence of AA $\mathrm{C}_{\mathrm{m}} \approx 2.1510^{-5} \mathrm{~F} \mathrm{~cm}^{-2}$.

The resistance of the membrane can be considered as a result of the presence of bilayer-thickness spanning pores, which are filled with the electrolyte solution. Thus, we can calculate the relative pore area fraction as usual:

$\mathrm{R}_{\mathrm{f}} / \mathrm{A}_{\mathrm{e}}=\mathrm{r}_{\mathrm{o}} \mathrm{L} / \mathrm{A}_{\mathrm{p}}$

where, $L$ is the length of the membrane ( $5 \mathrm{~nm}), A_{p}$ is the pore area, $A_{e}$ is the area of the electrode and $r_{o}$ is the resistivity of the electrolyte solution (16.67 $\Omega \mathrm{cm}$ ) (Zhang et al., 2018).

Hence, for the SLB covered electrode the pore fraction $A_{p} / A_{e}=r_{o}$ $\mathrm{L} / \mathrm{R}_{\mathrm{f}}=16.67 \Omega \mathrm{cm} \times 510^{-7} \mathrm{~cm} / 1.710^{6} \Omega \mathrm{cm}^{2} \approx 5 \times 10^{-12}$ while in the presence of $A A A_{p} / A_{e} \approx 2.810^{-12}$.

The presence of AA results in an increase in $R_{f}$ and a decrease in $C_{m}$ what is equivalent to a membrane with lower number of defects as calculated above.

Fig. S2 shows impedance data for a Au electrode modified by the SLB in solution $1 \mathrm{mM} \mathrm{Fe}(\mathrm{CN})_{6}{ }^{4-/ 3-}$ and $0.15 \mathrm{M} \mathrm{KCl}$ as supporting electrolyte. A single capacitive relaxation characterizes the measured impedance behavior which can be fitted to the impedance of the equivalent circuit shown in Fig. 14. Fig. 15 shows impedance data for an Au electrode covered by the SLB doped with Annonacin (Ann) in solution of buffer Tris. The same dynamic behavior as in Fig. S2 can be observed.

Best-fit parameters of impedance data in Figs. S2 and 15 are given in

Table 1

Best fit parameters resulting from the fitting of data in Figs. 14 and S1.

\begin{tabular}{cclll}
\hline & $\mathrm{R}_{\mathrm{e}} / \Omega$ & $\mathrm{Q} / \mathrm{s}^{\mathrm{n}-1} \mathrm{~F}$ & $\mathrm{n}$ & \multicolumn{2}{l}{$\mathrm{R}_{\mathrm{f}} / \Omega$} \\
\hline Au-SLB & $150 \pm 3$ & $(2.30 \pm 0.05) 10^{-6}$ & $0.90 \pm 0.01$ & $(1.7 \pm 0.1) 10^{6}$ \\
Au- SLB + & $260 \pm 5$ & $(1.60 \pm 0.03) 10^{-6}$ & $0.95 \pm 0.01$ & $(3.0 \pm 0.1) 10^{6}$ \\
AA & & & &
\end{tabular}

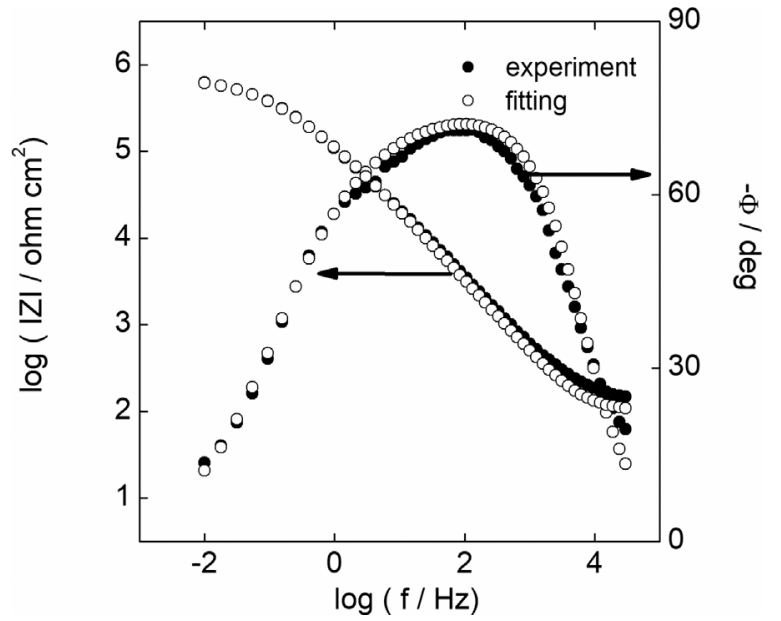

Fig. 15. Bode plots for experimental and fit impedance spectra measured with a $\mathrm{Au}$ electrode modified with the SLB doped with Ann in solution of the buffer tris and $1 \mathrm{mM} \mathrm{Fe}$ (CN) $64^{-} / 3^{-}$.

Table 2

Best-fit parameters resulting from the fitting of data in Figs. S2 and 15 .

\begin{tabular}{lcccc}
\hline & $\mathrm{R}_{\mathrm{e}} / \Omega$ & $\mathrm{Q} / \mathrm{s}^{\mathrm{n}-1} \mathrm{~F}$ & $\mathrm{n}$ & $\mathrm{R}_{\mathrm{f}} / \Omega$ \\
\hline $\mathrm{Au}-\mathrm{SLB}+\mathrm{Fe}(\mathrm{CN})_{6}{ }^{4-/ 3-}$ & 800 & $1.110^{-6}$ & 0.9 & $1.210^{6}$ \\
$\mathrm{Au}-(\mathrm{SLB}+\mathrm{Ann})+\mathrm{Fe}(\mathrm{CN})_{6}{ }^{4-/ 3-}$ & 150 & $1.010^{-6}$ & 0.9 & $7.610^{5}$ \\
\hline
\end{tabular}

Table 2. Values for the exponent $\mathrm{n}$ are close to 1 , indicating a capacitance behavior.

The membrane capacitance $C_{m}$ was calculated with the expression (2). Then, for the SLB covered electrode in solution $1 \mathrm{mM} \mathrm{Fe}(\mathrm{CN})_{6}{ }^{4-}$ / ${ }^{3-}$ results $\mathrm{C}_{\mathrm{m}} \approx 2.310^{-5} \mathrm{~F} \mathrm{~cm}^{-2}$ while for the SLB with Ann in the same solution $\mathrm{C}_{\mathrm{m}} \approx 1.610^{-5} \mathrm{~F} \mathrm{~cm}^{-2}$.

Regarding the pore fraction in these systems, for the SLB covered electrode in solution $1 \mathrm{mM} \mathrm{Fe}(\mathrm{CN})_{6}{ }^{4-/ 3-}$ can be calculated as follows (Cassier et al., 1999): $\mathrm{A}_{\mathrm{p}} / \mathrm{A}_{\mathrm{e}}=\mathrm{r}_{\mathrm{o}} \mathrm{L} / \mathrm{R}_{\mathrm{f}}=16.67 \Omega \mathrm{cm} \times 510^{-7} \mathrm{~cm} /$ $1.210^{6} \Omega \mathrm{cm}^{2} \approx 7 \times 10^{-12}$ while in the presence of Ann $\mathrm{A}_{\mathrm{p}} / \mathrm{A}_{\mathrm{e}} \approx 11$ $10^{-12}$

The presence of Ann in the lipid bilayer results in a decrease in $R_{m}$ and a decrease in $\mathrm{C}_{\mathrm{m}}$ what can be understood in terms of a membrane with a higher number of defects and with lower dielectric constant $\varepsilon$. This last feature being brought about by the incorporation of Ann into the hydrophobic region of the membrane as discussed above.

\section{Conclusions}

We investigated the interaction between two biomolecules (AA acid and Ann) with a bilayer lipid membrane. The results demonstrated that AA and Ann interact diffently with models of lipid bilayers that mimic the cell membrane.

At high molar ratios of AA, there is a loss of structured water molecules in both populations of the carbonyl group in the region of the polar head of the lipid. At $25{ }^{\circ} \mathrm{C}$ (liquid crystalline phase). On the other hand, Ann promotes the formation of hydrogen bonds with the carbonyl groups.

The $\mathrm{PO}_{2}{ }^{-}$antisymmetric stretching for the Ann:eggPC complex, is slightly affected towards higher frequencies with respect to the pure lipid. Consequently, Ann is expected to be able to induce the dehydration of the phosphate groups without the subsequent formation of $\mathrm{H}$ bonds with them. No significant changes are observed in the band frequencies of $\mathrm{PO}_{2}{ }^{-}$symmetric stretching $\left(1088 \mathrm{~cm}^{-1}\right)$, in both cases (AA:eggPC and Ann:eggPC complexes). This may be due to the fact that in the fluid state the polar groups are more hydrated, which makes the water displacement for biomolecules insertion more difficult. 
According to the electrochemical analysis, the interaction of AA with the supported lipid membrane does not alter its dielectric properties. This fact can be related to the conservation of structured water of the phosphate groups in the polar heads of the lipid. On the other hand, the incorporation of Ann into the lipid membrane generates an increase in the number of defects while changes the dielectric constant. This, in turn, can be associated with the induced dehydration of the phosphate groups.

\section{Conflict of interest}

We do not have conflicts of interests.

\section{Funding}

The authors gratefully acknowledge the Consejo de Investigaciones de la Universidad Nacional de Tucumán (CIUNT). This work was supported by the Agencia Nacional de Promoción Científica y Tecnológica with grants PICT $\mathrm{N}^{\circ}$ 2008-1902 and PICT-2014-1785.

\section{Acknowledgments}

C.A. Gervasi gratefully acknowledges the Comision de Investigaciones Científicas y Técnicas Buenos Aires (CICBA) for his position as a member of the Carrera del Investigador Científico. A. Ben Altabef is a member of the Research Career of CONICET (R. Argentina).

\section{Appendix A. Supplementary data}

Supplementary data associated with this article can be found, in the online version, at https://doi.org/10.1016/j.chemphyslip.2017.11.013.

\section{References}

Álvarez Colom, O., Neske, A., Chahaboune, N., Zafra-Polo, M.C., Bardón, A., 2009. A novel mono-tetrahydrofuranic acetogenin from annona montana, as a potent inhibitor of mitochondrial complex I. Chem. Biodivers. 6, 335-340.

Alvarez, P.E., Gervasi, C.A., Vallejo, A.E., 2007. Impedance analysis of ion transport through supported lipid membranes doped with ionophores: a new kinetic approach. J. Biol. Phys. 33, 421-431.

Bangham, A.D., Hill, M.W., Miller, N.G.A., 1974. Preparation and Use of Liposomes as Models of Biological Membranes. Methods in Membrane Biology. Plenum Press, New York, pp. 1-61.

Barnes, M.J., Kodicek, E., 1972. Biological hydroxylations and ascorbic acid with regard to collagen metabolism. Vitam. Horm. 1972 (30), 1-43.

Barrachina, I., Neske, A., Granell, S., Bermejo, A., Chahaboune, N., El Aouad, N., Álvarez Colom, O., Bardón, A., Zafra-Polo, M.C., 2004. A $\beta$-hydroxy- $\gamma$-lactone bistetrahydrofuranic acetogenin from annona cherimolia, is a potent inhibitor of mitochondrial complex I. Planta Med. 70, 866-868.

Bergera, N., Sachse, A., Bender, J., Schubert, R., Brandl, M., 2001. Filter extrusion of liposomes using different devices: comparison of liposome size, encapsulation efficiency, and process characteristics. Int. J. Pharm. 223, 55-68.

Bermejo, A., Figadere, B., Zafra-Polo, M., Barrachina, I., Estornell, E., Cortes, D., 2005. Acetogenins from Annonaceae: recent progress in isolation, synthesis and mechanisms of action. Nat. Prod. Rep. 22, 269-303.

Bonneau, N., Baloul, L., Bajin ba Ndob, I., Sénéjoux, F., Champy, P., 2017. The fruit of Annona squamosa L. as a source of environmental neurotoxins: from quantification of squamocin to annotation of Annonaceous acetogenins by LC-MS/MS analysis. Food Chem. 226, 32-40.

Brug, G.J., Van Den Eeden, A.L.G., Sluyters-Rehbach, M., Sluyters, J.H., 1984. The analysis of electrode impedances complicated by the presence of a constant phase element. J. Electroanal. Chem. 176, 275-295.

Caparros-Lefebvre, D., Sergeant, N., Lees, A., Camuzat, A., Daniel, S., Lannuzel, A., Brice, A., Tolosa, E., Delacourte, A., Duyckaerts, C., 2002. Guadeloupean parkinsonism: a cluster of progressive supranuclear palsy-like tauopathy. Brain 125, 801-811.

Carr, A.C., Frei, B., 1999. Toward a new recommended dietary allowance for vitamin C based on antioxidant and health effects in humans. Am. J. Clin. Nutr. 69, 1086-1107.

Cassier, T., Sinner, A., Offenhäuser, A., Möhwald, H., 1999. Homogeneity, electrical resistivity and lateral diffusion of lipid bilayers coupled to polyelectrolyte multilayers. Colloids Surf. B: Biointerfaces 15, 215-225.

Champy, P., Höglinger, G.U., Féger, J., Gleye, C., Hocquemiller, R., Laurens, A., Guérineau, V., Laprévote, O., Medja, F., Lombès, A., Michel, P.P., Lannuzel, A., Hirsch, E.C., Ruberg, M., 2004. Annonacin, a lipophilic inhibitor of mitochondrial complex I, induces nigral and striatal neurodegeneration in rats: possible relevance foratypical parkinsonism in Guadeloupe. J. Neurochem. 88, 63-69.
Champy, P., Melot, A., Guérineau Eng, V., Gleye, C., Fall, D., Höglinger, G.U., Ruberg, M., Lannuzel, A., Laprévote, O., Laurens, A., Hocquemiller, R., 2005. Quantification of acetogenins in Annona muricata linked to atypical parkinsonism in Guadeloupe. Mov. Disord. J. 20, 1629-1633.

Chen, Yong, Chen, Yayun, Shi, Yeye, Ma, Chengyao, Wang, Xunan, Li, Yue, Miao, Yunjie, Chen, Jianwei, Xiang, Li, 2016. Antitumor activity of Annona squamosa seed oil. J. Ethnopharmacol. 193, 362-367.

Cort, W.M., 1982. Antioxidant properties of ascorbic acid in foods. In: Seib, P.A., Tolbest, B.M. (Eds.), Ascorbic Acid Chemistry, Metabolism and Uses, Adv. Chem. Ser. N. 200 P531. American Chemical Society, Washington, DC, USA.

Díaz, S.B., Amalfa, F., Biondi de López, A.C., Disalvo, E.A., 1999. Effect of water polarized at the carbonyl groups of phosphatidylcholines on the dipole potential of lipid bilayers. Langmuir 15, 5179-5182.

Díaz, S.B., Biondi de López, A.C., Disalvo, E.A., 2003. Dehydration of carbonyls and phosphates of phosphatidylcholines determines the lytic action of lysoderivatives. Chem. Phys. Lipids 122, 153-157.

Di Toto Blessing, L., Ramos, J., Diaz, S.B., Ben Altabef, A., Bardón, A., Brovetto, M., Seoane, G., Neske, A., 2012. Insecticidal properties of annonaceous acetogenins and their analogues. interaction with lipid membranes. Nat. Prod. Commun. 7 (9), 1215-1218.

Disalvo, E.A., de Gier, 1983. Contribution of aqueous inter- phases to the permeability barrier of lipid bilayer for non-electrolytes. J. Chem. Phys. Lipids 32, 39-47.

Disalvo, E.A., Lairion, F., Díaz, S.B., Arroyo, J., 2002. Physical chemistry of lipid interfaces: state of hydration, topological and electrical properties. In: Condat, C.A., Baruzzi, A. (Eds.), Recent Research Developments in Biophysical Chemistry. Research Signpost, India.

Du, L., Liu, X., Huang, W., Wang, E., 2006. A study on the interaction between ibuprofen and bilayer lipid membrane. Electrochim. Acta 51, 5754-5760.

Escobar-Khondiker, M., Höllerhage, M., Muriel, M., Champy, P., Bach, A., Depienne, C., Respondek, G., Yamada, E.S., Lannuzel, A., Yagi, T., Hirsch, E.C., Oertel, W.H., Jacob, R., Michel, P.P., Ruberg, M., Höglinger, G.U., 2007. Annonacin, a natural mitochondrial complex I inhibitor, causes tau pathology in cultured neurons. J. Neurosci. 27, 7827-7837.

Fana, S., Zhaoa, M., Dinga, L., Lib, H., Chen, S., 2017. Preparation of Co3O4/crumpled graphene microsphere as peroxidase mimetic for colorimetric assay of ascorbic acid. Biosens. Bioelectron. 89, 846-852.

Fox, C.B., Harris, J.M., 2010. Confocal Raman microscopy for simultaneous monitoring of partitioning and disordering of tricyclic antidepressants in phospholipid vesicle membranes. J. Raman Spectrosc. 41, 498-507.

Fox, C.B., 2007. Detecting phase transitions in phosphatidylcholine vesicles by Raman microscopy and self-modeling curve resolution. J. Phys. Chem. B 111, 11428-11436.

Garber, M.H., Abd el Halim, N.A., Khalil, W.A., 2002. Antioxidant activity of ascorbic acid against peroxidation of phosphatidylcholine liposomes exposed to gamma radiation:a synergistic interaction? Rom. J. Biophys 12, 103-115.

Goedert, M., Ghetti, B., Spillantini, M.G., 2000. Tau gene mutations in frontotemporal dementia and parkinsonism linked to chromosome 17 (FTDP-17). Their relevance for understanding the neurogenerative process. Ann. N.Y. Acad. Sci. 920, 74-83.

Gutiérrez-Quequezana, L., Vuorinen, A.L., Kallio, H., Yang, B., 2018. Improved analysis of anthocyanins and vitamin C in blue-purple potato cultivars. Food Chem. 242, $217-224$.

Höllerhage, M., Matusch, A., Champy, P., Lombès, A., Ruberg, M., Oertel, W.H., Höglinger, G.U., 2009. Natural lipophilic inhibitors of mitochondrial complex I are candidate toxins for sporadic neurodegenerative tau pathologies. Exp. Neurol. 220, $133-142$.

Hübner, W., Blume, A., 1998. Interactions at the lipid-water interface. Chem. Phys. Lipids $96(1-2), 99-123$.

Head, K.A., 1998. Ascorbic acid in the prevention and treatment of cancer. Altern. Med. Rev. 3, 175-186.

Hollis, L.S., Amudsen, A.R., Stern, E.W., 1985. Synthesis, structure and antitumor properties of platinum complexes of vitamin C. J. Am. Chem. Soc. 107, 274-276.

Lachapelle, M.Y., Drouin, G., 2011. Inactivation dates of the human and guinea pig vitamin C genes. Genetica 139 (2), 199-207.

Lannuzel, A., Michel, P.P., Höglinger, G.U., Champy, P., Jousset, A., Medja, F., Lombès, A., Darios, F., Gleye, C., Laurens, A., Hocquemiller, R., Hirsch, E.C., Ruberg, M., 2003. The mitochondrial complex I inhibitor annonacin is toxic to mesencephalic dopaminergic neurons by impairment of energy metabolism. Neuroscience 121, 287-296.

Lannuzel, A., Höglinger, G.U., Verhaeghe, S., Gire, L., Belson, S., Escobar-Khondiker, M., Poullain, P., Oertel, W.H., Hirsch, E.C., Dubois, B., Ruberg, M., 2007. Atypical parkinsonism in Guadeloupe: a common risk factor for two closely related phenotypes? Brain 130, 816-827.

Lee, I.M., 1999. Antioxidant vitamins in the prevention of cancer. Proc. Assoc. Am. Phys. 111 (1), 10-15.

Levine, M., 1986. New concepts in the biology and biochemistry of ascorbic acid. N. Engl. J. Med. 314 (14), 892-902.

Mantsch, H.H., McElhaney, R.N., 1991. Phospholipid phase transitions in model and biological membranes as studied by infrared spectroscopy. Chem. Phys. Lipids 57, $213-226$.

Olson, F., Hunt, C.A., Szoka, F.C., Vail, W.J., Papahadjopoulos, D., 1979. Preparation of liposomes of defined size distribution by extrusion through polycarbonate membranes. Biochim. Biophys. Acta 557, 9-23.

Patterson, R.E., White, E., Kristal, A.R., Nuehouser, M.L., Potter, J.D., 1997. Vitamin supplements and cancer risk: the epidemiologic evidence. Cancer Causes Contr. 8 786-807.

Pohle, W., Selle, C., Fritzsche, H., Binder, H., 1998. Fourier transform infrared spectroscopy as a probe for the study of the hydration of lipid self-assemblies. I. 
Methodology and general phenomena. Biospectroscopy 4, 267-280.

Prasad, K.N., Kumar, A., Kochupillai, V., Cole, W.C., 1999. High doses of multiple antioxidant vitamins: essential ingredients in improving the efficacy of standard cancer therapy. J. Am. Coll. Nutr. 18, 13-25.

Purrucker, O., Hillebrandt, H., Adlkofer, K., Tanaka, M., 2001. Deposition of highly resistive lipid bilayer on silicon-silicon dioxide electrode and incorporation of gramicidin studied by ac impedance spectroscopy. Electrochim. Acta 47 (5), 791-798.

Rameshkumar, S., Kumaravel, M., 2017. Changes in the electrical properties of agargel supported bilayer lipid membrane brought about by midazolam. Electrochim. Acta 245, 489-496.

Rivas, C.I., Vera, J.C., Guaiquil, V.H., Velasquez, F.V., Borquez-Ojeda, O.A., Carcamo, J.G., Concha, I.I., Golde, D.W., 1997. Increased uptake and accumulation of vitamin C in human immunodeficiency virus 1-infected hematopoietic cell lines. J. Biol. Chem. 272, 5814-5820.

Rohaizad Md Roduan, M., Abd Hamid, R., Sulaiman, H., Mohtarrudin, N., 2017. Annona muricata leaves extracts prevent DMBA/TPA-induced skin tumorigenesis via modulating antioxidants enzymes system in ICR mice. Biomed. Pharmacother. 94 481-488.
Salama, M., Arias-Carrión, O., 2011. Natural toxins implicated in the development of Parkinson's disease. Ther. Adv. Neurol. Disord. 4, 361-373.

Singh, P., Singh, N.P., Yadav, R.A., 2010. Study of the optimized molecular structures and vibrational characteristics of neutral $\mathrm{L}$-ascorbic acid and its anion and cation using density functional theory. J. Chem. Pharm. Res. 2, 656-681.

Snyder, R.G., Strauss, H.L., Elliger, C.A., 1982. C-H stretching modes and the structure of n-alkyl chains. 1. Long, disordered chains. J. Phys. Chem. 86, 5145-5150.

Steinem, C., Galla, H.J., Janshoff, A., 2000. Interaction of melittin with solid supported membranes. Phys. Chem. 2, 4580-4585.

Trojanowski, J.Q., Lee, V.M., 2005. Pathological tau: aloss of normal function ora gain in toxicity? Nat. Neurosci. 8, 1136-1137.

Vieira Machado de Moraes, I., Riceli Vasconcelos Ribeiro, P., Schmidt, F.L., Marques Canuto, K., Zocolo, G., Sousa de Brito, J., Luo, E.R., Richards, K.M., Tran, K., Smith, R.E., 2016. UPLC-QTOF-MS and NMR analyses of graviola (Annona muricata) leaves. Braz. J. Pharmacogn. 26, 174-179.

Zhang, L., Wang, G., Wu, D., Xiong, C., Zheng, L., Ding, Y., Lu, H., Zhang, G., Qiu, L., 2018. Highly selective and sensitive sensor based on an organic electrochemical transistor for the detection of ascorbic acid. Biosens. Bioelectron. 100, 235-241. 